\title{
The Social Construction of Congenital Deafblindness in relation to Education: Analysis of focus groups in East and Central Africa
}

\author{
Ismael K. Byaruhanga, Anne V. Nafstad \& Jacques Souriau
}

\begin{abstract}
This study investigated the importance of social construction of congenital deafblindness (CDB) when planning special needs education services. The study was conducted in Uganda and the Democratic Republic of the Congo (DRC). The research was based on a literature review and a focus group study. In the focus groups a dialogical perspective was used for acquiring knowledge through communicative interactions. The focus was on two main topics: social construction of Congenital Deafblindness (CDB) and knowledge about education services for people with CDB. Fourteen participants were selected, with seven from each country. Participants were familiar with deafblind persons and/or with communities where they lived. The grounded theory approach and thematic analysis method were used to determine the correct coding and themes and identify patterns of meaning of different opinions. The results of the data analyses showed that participants attributed the causes of CDB in Uganda and the DRC to cultural and religious beliefs. The medical stance on CDB was less understood. In addition, culture and religion were identified as dominant factors in the social construction of the position of people with CDB in the community, leading to misunderstanding and inappropriate services for them. This community misunderstanding indicates that people at the local level are likely to stick to traditional and religious practices. Therefore, changing attitudes and educational opportunities for people with CDB requires more understanding of third-party voices and the underlying barriers in these communities.
\end{abstract}

\section{Keywords}

social construction, congenital deafblindness, special needs education, culture and religion, community. 


\section{Introduction}

Deafblindness is not a new global phenomenon (EDbN, 2014; WHO, 2011; McInnes, 1999; van Dijk, 1997; Souriau, 2000, 2002, 2007). According to the European Deafblind Network (EDbN, 2014), deafblindness is now more frequently reported and widely recognised than ever before. This rise in recognition and reporting continues. However, in many countries "deafblindness" remains a poorly defined condition with many misunderstandings concerning its causes, the variations in impairment experienced by individuals, and its impact on everyday life (Larsen \& Damen, 2014). Other factors, such as different cultural beliefs, may also lead to a misunderstanding of the condition of people with CDB. Furthermore, these factors can have a negative impact on the education of deafblind people.

According to the European Agency for Special Needs and Inclusive Education (2013) and the United Nations (2006), the social construction of deafblindness in Europe in relation to education has been positively shaped by the position of international organizations working in the field of disabilities, whose approach is based on the universal right to education. In addition, universal instruments and institutions advocating on behalf of people with disabilities have strengthened their voices, which has also influenced social change and protected the identity of people with CDB (Nafstad \& Rødbroe, 2015; Hart, 2010; Janssen \& Rødbroe, 2007; Rødbroe \& Janssen, 2006; Van Dijk. 1997). There is now a greater understanding of the nature of disabilities and the associated personal capacities and limitations in pursuing a dynamic and progressive education (Chandra \& Sharma, 2004; Peters, 1975; Dantona, 1971; McLetchie, 1993; Collins, 1995; Crow \& Crow, 1964). Consequently, the universal right to education and other international tools for those with special needs are perceived as a social reality, based on a common understanding constructed between nations and people for social change (Burr, 2003).

In Africa, this social reality may differ from one country to another depending on cultural values and different cultural positions the societies associate with disability in general (Eiesland, 1994; Riddell \& Watson, 2014; Bunning et al, 2017). In Central and Eastern Africa, the available literature does not provide relevant information on the social construction of $\mathrm{CDB}$ in relation to education. The few studies that have been conducted are primarily focused on the teaching methodology for people with deafblindness in general (Omuguru, 2016; UNICEF-Uganda, 2014; Signo, 2014), with less focus on the universal right to education compared to research in Europe.

Similarly, the information gathered reveals that little is known about how CDB is socially constructed in education in East and Central Africa. Therefore, this study was aimed analysing the social construction of people with CDB in these both countries in order to be 
able to formulate recommendations for further research and future education for people with CDB.

The main research question for this study was: To what extent can the cultural position and attitude towards people with CDB in Uganda and DRC be described in relation to education?

\section{Theoretical framework}

This study was guided by dialogical theory, which describes the human ability to create meaning in relation to the social and physical environment (Linell, 1998; 2009; Nafstad \& Rødbroe, 2015). This theory also describes the human ability to understand social realities and their influences through cultures from historical perspectives (Markova, 2016). As social problems are constructed in specific cultures at a particular time or period (Lane, 2010), this theory oriented the study to explore how different communities in East and Central Africa understand CDB, what meaning they ascribe to it, and how the construction of normality and disability through cultural diversity can influence educating people with CDB. Investigating how CBD is socially constructed includes the identification of barriers such as the differences in the values and beliefs (Bunning et al., 2017; Shakespeare, 2014; MacDonald, 2012) about CDB, the tensions emanating from a lack of reciprocal interaction between culture and religion (Eiesland, 1994), the medical stance on CDB, and the identification of "third party voices", characterised by a mental image (Janssen \& Rødbroe, 2007) which is associated with 'God' or 'gods' as a third person with power who probably has contributed to the state of CDB intentionally.

In A Silent Exile on this Earth: The Metaphorical Construction of Deafness in the Nineteenth Century, Baynton (2006) argues that 'deafness is a cultural construction'. From the same perspective, it can be argued that 'deafblindness is a cultural construction', meaning that it is constructed against the norms and standards of what society perceives to be normal (Michalko, 2002). In addition, each society has its way of seeing, understanding, analyzing, and interpreting a given situation or interpreting a situation in relation to an event. As Berger (1966) indicates, 'society was created by humans, but this creation turns around and molds humans every day'. This process is explained by the strength of dynamics of a group, which may favour certain attitudes, beliefs, or opinions according to the relationships between internal and external dialogue in a specific society and thus creates a certain culture (Bakhtine, 1970). Moreover, group influence in a society can become significant, positively or negatively influencing the community's perceptions of certain conditions such as disability. Therefore, $\mathrm{CDB}$ as a social condition can be constructed from a subjective, personal, and 
culturally determined point of view. From this perspective, the education of people with CDB could be perceived differently in each country due to cultural diversity.

\section{Methods}

\section{Study design}

An analytical framework inspired by dialogical theory was adapted for this study to develop a deeper understanding of the social construction of CDB in relation to education in East and Central Africa. The dialogical approach was designed to mirror different barriers, tensions, and third-party voices surrounding the social image of a person with CDB in the community (Gillespie \& Cornish, 2009).

Focus groups were used to obtain several viewpoints about the participants' personal contexts, experiences, beliefs, perceptions, and attitudes through a moderated interaction (Nyumba et al., 2018). The grounded theory approach and thematic analysis methods were used, respectively, to determine the correct coding and themes and identify patterns of meaning related to convergence and divergence of opinions. The main research question was leading, structured by two main subthemes: 1) social construction of CDB divided in: a) causes of CSB, b) role of people with CDB in the community, c) role of the church or religion, and 2) educational considerations, divided in a) provision of services, b) educational opportunities, c) possibilities for future services. Finally, the data were interpreted based on the main themes within the topics and a conceptual framework was designed (Charmaz, 2005).

\section{Location of the study}

The study was conducted in two countries. The first country, Uganda, located in East Africa, was selected on the basis that for more than ten years international organisations, such as Sense International (UK), the Perkins School for the Blind (US), and Royal Dutch Kentalis (the Netherlands), have implemented education programmes for deafblind people and organized parent support groups.

The second country, the DRC, located in Central Africa, was selected because although there are families with persons who are deafblind, there is no appropriate structure for their education, either from the government or from local or international organizations. In summary, one country has education programmes for people with $\mathrm{CDB}$, and the other does not. This difference could be important in understanding the social realities of CDB in relation to education. 


\section{Selection and consent of the participants}

Fourteen participants were selected based on their experience and knowledge (Orodho, 2012), with seven from each country. In addition, the participants were selected from villages where people with CDB lived. The rationale for this selection was that these individuals would be familiar with the condition as opposed to those from other communities where there are no cases of CDB. Besides the parents of the children with CDB, other targeted participants aged 40 years or older, because age plays an important role in African culture, where being older is a strong cultural position and older people are considered to possess power that maintains certain values and beliefs in society (Obioha \& T'soeunyane, 2012). For each country were selected: parents from a child with CDB, one neighbour, one local leader, one church leader, one traditional healer and one health care professional.

In Uganda, the researcher collaborated with Sense International Uganda to select a suitable family for the study. From a list of families having children with CDB, a family with three-year old twins was selected. The twins were born congenitally deafblind after the mother contracted German measles. Choosing a mother of twins was also important because twins in Africa are regarded as either a burden or a gift from God (Peek, 2011). Additionally, the dual factors of being twins and congenitally deafblind offers greater potential for cultural and religious interpretations.

In the DRC, the researcher collaborated with the Centre for Education and Community-Based Rehabilitation and a local traditional chief, who identified a family with seven children, all with CDB. The youngest was aged eight and the oldest, twenty-five. These children had never participated in any education programmes. The selection of this family was primarily based on the accessibility of the village, and more importantly because of the presence of seven deafblind children in the same family. As mentioned earlier about the twins in Uganda, the presence of more than one child in the same family triggers further questions and cultural and religious interpretations.

Researcher and research team. The researcher was director and master student in Pedagogical Sciences, Track Communication and Deafblindness. He collaborated with research assistants. In Ugunda the research assistants were a qualified teacher for the deaf, a social worker, and a cameraman, and in DRC a qualified teacher for the deaf and a psychologist and a cameraman. The assistants took in depth notes during the focus group discussions. In Uganda one assistant took the role of interpreter. The cameramen took the video-recordings. The researcher had the lead of the focus groups. 
Regarding the ethical aspect, the participants provided written consent for their discussions in the focus groups to be video recorded. The participants reviewed the video to confirm their opinions on the research questions.

\section{Focus group procedure}

\section{Focus groups}

Two discussion groups were organised for each country; that means four focus group discussions in total. In the first group the parents of the children with CDB were included and in the second group no parents were included. The second group existed mainly from participants who were important in the community around the children with CDB, such as the local leader and the church leader (see selection). The purpose of the discussions was that the participants felt free to share their opinions on questions concerning deafblindness as well as their cultural experiences. This division into two groups was made because in the presence of a parent of a child with CDB, other members were found to be more reserved and less likely to give a clear picture of their attitudes and beliefs regarding CDB. In other words, dividing the group into two made it possible to avoid social prejudices linked to emotions such as embarrassment (Gillespie and Cornish, 2009).

\section{Determining the questions}

Before the study started, a series of meetings were organized with education leaders, administrative leaders, and national organizations, working in the field of deafblindness. In these meetings study aims and procedures were explained in order to obtain participants' input and permission to reach out to people in the field.

The focus group discussions were structured around two specific topics in relation to the research question. The topics were presented in such a way that the participants would provide detailed information and thinking rather than simple answers (Ary et al., 2010). There were two major topics, each with three sub-topics:

(1) Approach and construction of the cultural position of CDB/Approche et construction de la position culturelle de la Surdicécité Congénitale

1.1 What causes do the community attribute to CDB ?Quelles sont les causes attribuées à la Surdicécité Congénitale par la communauté?

1.2 What is the role or place in the community of the person with CDB?/Quel est le rôle/la place de la Surdicécité Congénitale dans la communauté? 
1.3 What are your experiences with the church in relation to CDB?Quelles sont vos expériences avec l'Église par rapport à la Surdicécité Congénitale?

(2) Education and services for people with $\mathrm{CDB} /$ Education et services pour les personnes avec Surdicécité Congénitale

2.1 Are there services that provide care for people with CDB?/Existe-t-il des services qui prennent en charge la personne avec Surdicécité Congénitale?

2.2 Do you know if there are any educational opportunities for this child?/Savez-vous s'il y a des opportunités éducatives pour cet enfant?

2.3 How should services be organized to care for people with CDB (future considerations): culture, church, education, government, NGOs?/Comment les services devraient-ils être organisés pour prendre soin de la Surdicécité Congénitale (considerations futures): culture, église, éducation, gouvernement, NGOs?

\section{Facilitation during meetings}

In Uganda, the discussions were held in English under the facilitation of the researcher. Nevertheless, for a better understanding, the assistant researcher played the role of interpreter in Luganda for further explanation. In the DRC, the discussions were conducted in Lingala and French; no interpreter was needed because the participants and the research team were comfortable speaking Lingala.

The meeting was organised in such a way that all participants were requested to share their opinions, while respecting their position and function in society. The group discussions were video recorded to ensure a complete recording of everything that was said. Each focus group lasted approximately 45 minutes, and the videos were subsequently reviewed by the researcher and the participants of the focus group to confirm the accuracy of their views and allow time for additional comments. To increase credibility (Spradley, 1980), the study team comprised four people (see selection).

\section{Ethical consideration}

Written consent was obtained from each participant, and ethics was approved for the study from the committee board of the Master track Communication and Deafblindness of the University of Groningen. Participants were informed and consulted on the results of the study. 


\section{Data analysis}

To understand the cultural position on $\mathrm{CDB}$, the grounded theory approach and thematic analysis methods were used, respectively, to determine right coding and themes and identify patterns of the meaning of different opinions from answers to the research questions (Czarniawska, 2004; Nyumba et al., 2018; Ary et al., 2010). Simply put, this labelling or coding process enabled quick retrieval and examination of all the texts associated with key thematic ideas. Thus, it allowed an understanding of the social constructions of CDB and the considerations on education services. The findings were interpreted and presented in narrative form (Charmaz, 2005).

\section{Results}

\section{Analysis regarding sub questions}

Before being able to answer the main question of this study, 'To what extent can the cultural position and attitude toward people with CDB in East and Central Africa be described in relation to education?', first the results of the different subtopics are described. A more extensive overview of the results is described in the master thesis (Byaruhanga, 2018).

The answers to the first sub-question (1.1), 'What causes does the community attribute $\mathrm{CDB}$ to?' revealed that, in both Uganda and the DRC, the causes of CDB are more often attributed to cultural and religious beliefs. The medical stance on CDB is less understood, even by some medical and educational staff. This diversity in understanding of the causes of $\mathrm{CDB}$ has created gaps between the medical state of the art prevalent among organisations or institutions working in the CDB field, and that of the local population, who believe in traditional and religious practices. For example, in Uganda, the mother of the twins with CDB reported, 'I have this problem because a friend of mine advised me to use a family planning method'. She believed that the family planning measure was the cause of the disability. However, in Mulago Hospital, the doctors stated that it was because of German measles.

In the DRC, participants talked of 'possession by evil spirits and charms' at home in the form of leaves called Lianga, which can be planted at the farm and used for hunting. When health failure occurs, the charm can turn against the owner and cause disability or death. 
Regarding the second sub-question (1.2), 'What is the role or place in the community of the person with CDB?', findings based on the participants' opinions indicate that tension still exists in understanding the role or place of people with CDB in Uganda and the DRC. This tension creates conflicting intentions, which again leads to confusion in determining the position and role of people with CDB in a community.

For example, opinions from participants were more rigid, for example, 'These children are useless. They cannot learn. They have to stay at home'. A participant in Uganda, who was a neighbour of the children with CDB said, 'These children are not important, because even if a visitor arrives at the house, they are unable to call the mother and report any information'. The same opinion was shared by the medical practitioner from the DRC who said, 'Since these children cannot see and cannot hear, they are not important; they are a burden to their parents'.

Regarding the answers to the third sub-question (1.3), 'What are your experiences with the role of the church in relation to CDB?', it was found that the church demonstrated a strong conviction about the third party, God, and because of the significance given to this third voice, the church considers people with $\mathrm{CDB}$ to be those in need of help. According to the participants, the church primarily encourages parents of people with CDB to pray or attend church services to receive help from well-wishers. This social construction based on the participants' religious beliefs can lead to not prioritizing the education of people with CDB.

Results related to the question concerning the provision of services for people with CDB (2.1) revealed that in both countries people at the local level, especially in rural areas, were not aware of the organizations or institutions offering services for people with CDB. This lack of services and information can result in the fact that people at the local level continue with traditional and religious practices. For example, despite the presence of international organizations, such as Perkins School for the Blind (US), Kentalis (the Netherlands), Signo (Norway), Visio (the Netherlands), and Sense International (UK), a participant from Uganda, who was a local chief, reported, 'There are many organisations we hear support people with disabilities, but they are not present at the community level'. Moreover, during the interview, the community-based supervisor from Sense International Uganda stated, '...even if these twin children with CDB are under our rehabilitation programme, sometimes the mother takes them to a witch doctor for treatment'. This example shows a lack of collaborative dialogue between international organizations and between organizations and the community, leading to a lack of coherence in services for people with CDB.

With regard to sub questions 2.2 the educational opportunities of children with CDB and 2.3 future support by organizations, participants from both countries argued that 
'children with CDB have fewer opportunities to learn' and 'the government should take responsibility' to provide proper services for them'. These answers identified the need for good dialogue among partners working in the field of CDB to jointly collaborate and improve the implementation of educational programmes adapted to the needs of people with CDB. The involvement of parents and the community is of paramount importance for the sustainability of such programmes.

\section{Reflection on and interpretation of results in conceptual models}

With regard to the topic of social construction of CDB in the community the framework presented in Figure 1 is developed. On religious values of people with CDB, the participants in this study argued that people with CDB should attend church services because by doing so, well-wishers and other believers can offer help and pity them. It is possible that religious beliefs driven by the conviction of the third voice encourage people with CDB to initiate practices such as begging or taking to the streets as their religious stance tells them their role is to be helped by others. This finding is consistent with the literature showing that people with disability are considered objects of pity (Michalko, 2002; Kreigel, 1987). Using the social construction of CDB based on the participants' opinion and stance, negative consequences for the everyday life of people with $\mathrm{CDB}$ are summarized in Figure 1.

On the topic of education and services the framework in Figure 2 is developed. The term community-based can mean a participatory process requiring effective dialogue and collaboration from various stakeholders at the local level seeking to understand their different realities and looking for solutions to effect social change (MacDonald, 2014). This conceptual framework highlights the way dialogue and collaboration can be built. NGOs, health institutions, etc. must first start with advocacy and training (1) of community leaders who must already have been persuaded (in favour of their respective communities).

Figure 1: Framework on people with CDB's place in the community and consequences

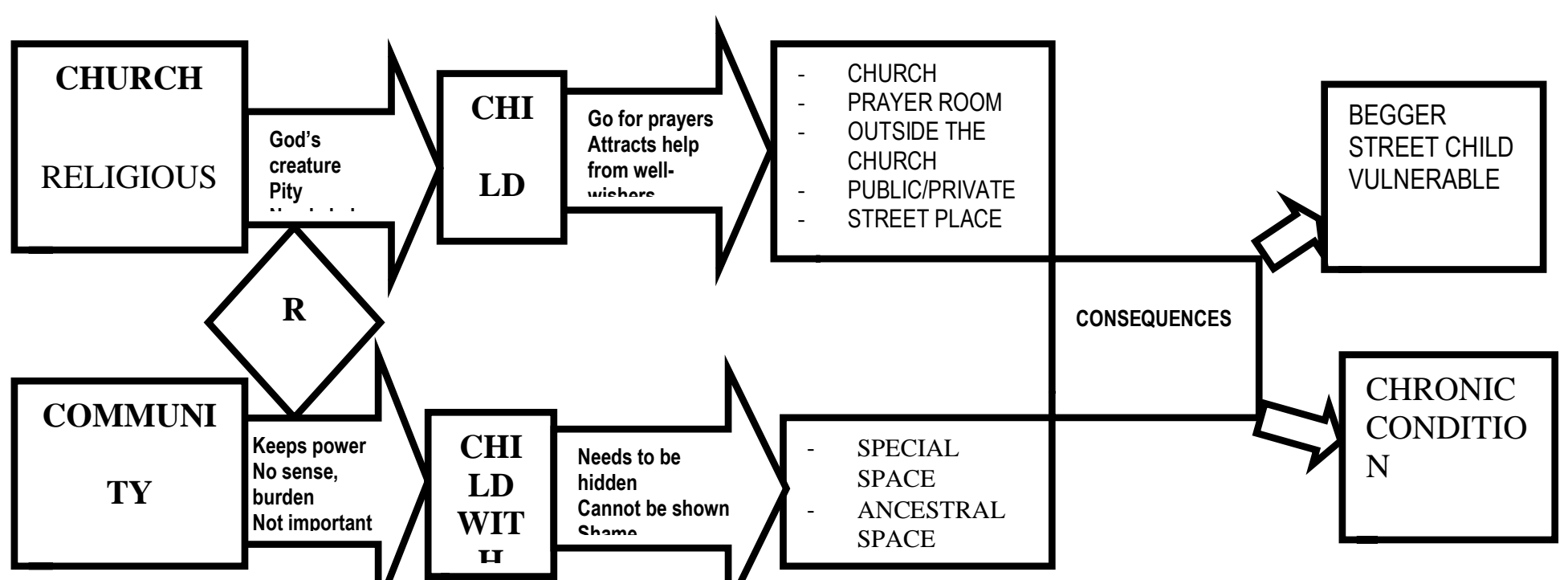


This follows the literature which stresses that the success of an educational programme in a given community (varying by culture) should be based on the positive beliefs of that society (Dewey, 1916). This implies that for the education of people with CDB to be successful their position in a community must be properly understood. Once the community leaders understand they will in turn disseminate the information to their respective bases (2), each one according to their stance. This can be through a mutual dialogue with the aim of building mutual trust to achieve social change. The community base will embrace the message if it comes from their local leaders because they share the same beliefs, culture and values, leading to a good understanding of the disability (CDB) (3).

Figure 2: Framework on Community-based education approach to people with CDB

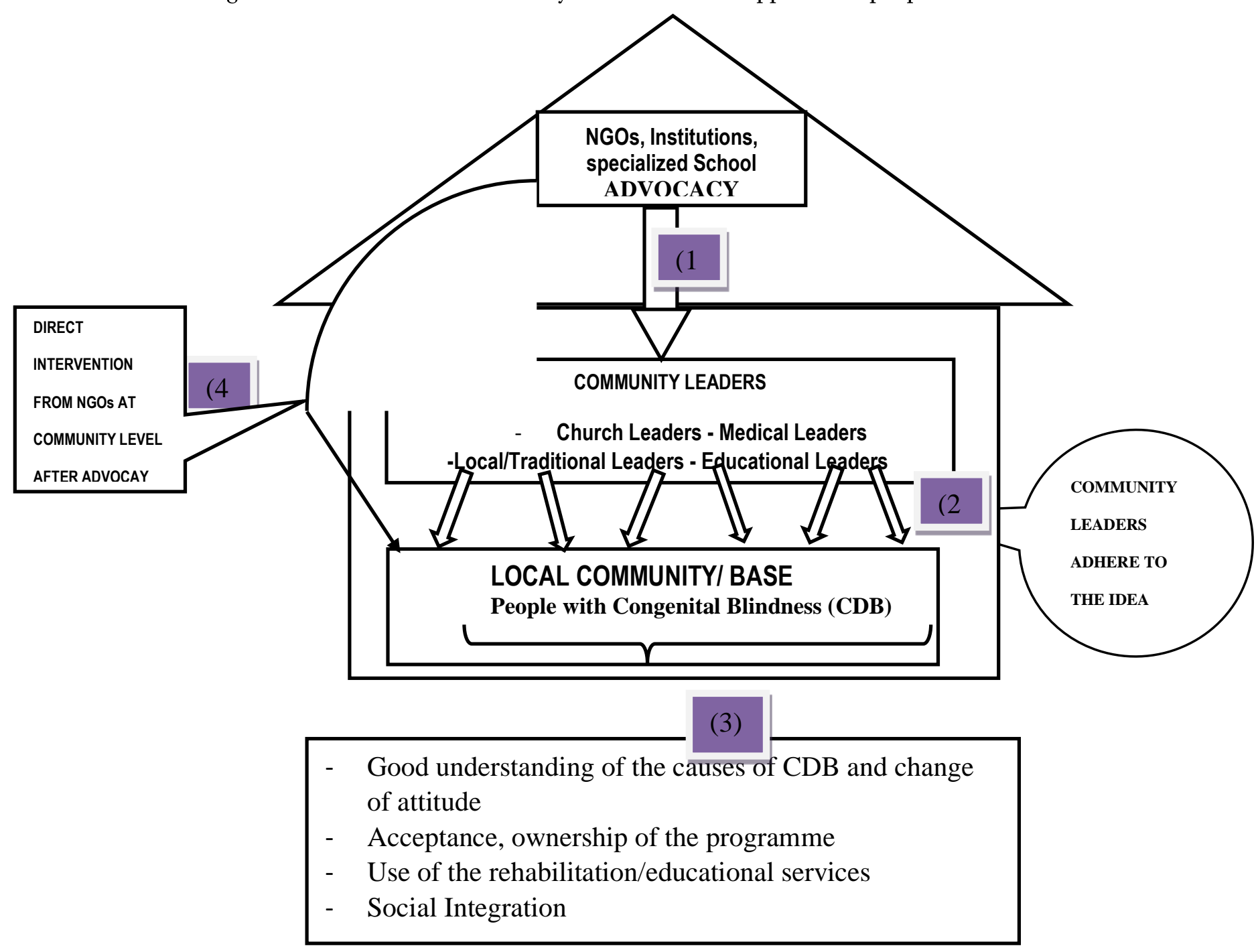

In addition, the community base should understand the need: the demand should come from within. This is consistent with the literature stipulating that education is the development of an individual according to their needs and the demands of society (Chandra \& Sharma, 2004). The literature also stresses that schooling should take place in a local context where cultural 
beliefs and values have strong influence (MacDonald, 2014). If a successful intervention within the community is to be achieved NGOs can implement an education programme (4) only after interventions from community leaders.

\section{Conclusion and Discussion}

Regarding the main question of this study, 'To what extent can the cultural position and attitude toward people with CDB in East and Central Africa be described in relation to education?' it can be concluded that in both countries, culture and religious beliefs are major factors in the social construction of people with CDB. Additionally, culture and religion are perceived as strong instruments that can influence change in society. Therefore, understanding the third-party voices and the underlying barriers and tensions surrounding people with $\mathrm{CDB}$ is important, in gaining knowledge about the position of $\mathrm{CDB}$, and thus, in planning educational services in a multicultural context.

\section{Reflections on dialogicality in relation to religious stance}

Before discussing the results more in depth, first some reflections on the dialogical perspective in this study. From a dialogical perspective, the idea of 'fellowship with others to maintain a sense of life' triggers the role of 'others'. The church offers the role of 'others' in the form of people as direct partners and 'God' (who is invisible) as the third party (Linell, 1998, p. 13), giving them a powerful voice believed to be capable of healing afflictions. This study reveals that the parents of children with CDB go to church with two aims: to receive help from well-wishers and to communicate their social realities to 'God'.

As predominately Christian countries, people in Uganda and the DRC have great faith in the Bible while simultaneously maintaining certain cultural practices, as these two instruments - religion and culture - seem to have strong voices that influence social realities, thoughts, and even the position of an individual in the community. Hart (2010) pointed out that one way to understand communication about social realities in terms of the other is to explore how partners share attention between people, objects, places, and events. It appears that the parents believe that God can improve the condition of their child. They hope that God will engage with them in their concerns for their child, so that their trust in God makes the child a third element of shared concern. However, the question is, through this type of intersubjectivity, how do parents explain God's attention to CDB? How do they assess the success and failure of this communication in relation to a change in attitude and access to education? This sharing of subjective states may indicate that there is a deep inner dialogue between the parents of people with CDB and God for the sake of the child. 


\section{Reflection on the most important outcomes of the study}

The most important outcome of this study was 'the identification of the third voice' in the religious stance. This third voice, that of 'God', is understood to have great power. This means that religious followers have their ideas about people with $\mathrm{CDB}$, with descriptions such as the following: 'God's creatures'; 'They exist to show the power of God'; 'They need to keep praying or attending church services to receive help from well-wishers'. Similarly, those who follow traditional values have the perspective that there is another invisible strong 'God/Spirit' connected to the children with CDB: 'Children with CDB contain certain forces or power from spirits within them'. This difference in viewpoints between the two forces (religion and traditional perspective), not only creates social and cultural tension but also negatively affects the children by minimising their strengths and skills and hindering their educational possibilities. Additionally, there is no interaction or dialogue between the two stances to create a positive constructed meaning of CDB (Linell, 1998). Therefore, social and community dialogue is necessary to minimise the negative result of the dominant social power that has culturally emerged in the community.

The second useful outcome, is the gap observed between the medical stance of international organisations providing services for people with CDB and the attitude of the local population who believe in religious and traditional values. This finding is in line with the idea that each society has its own way of seeing, understanding, analysing, and interpreting a given situation (Berger, 1966). For example, the Western perspective of the US and Europe regarding the education of people with CDB may not be the same as that of Africa. In any case, understanding this inequality in the construction of social realities is important (Nafstad \& Rodbroe, 2015).

The third important outcome is that focus groups demonstrated to be a good method for gaining an in-depth understanding of the construction of social realities (Nyumba et al., 2018). Culturally, in African communities, elders typically construct stories based on traditional and cultural knowledge (Mji et al., 2017, p. 38). This knowledge is normally shared in groups and passed on to the next generation. In this study, the focus group allowed a more complex personal reporting of experience from the participants about their beliefs, attitudes, and ideas about $\mathrm{CDB}$ and created a flow of meaningful conversation between the participants. As Flores and Alonso (1995) have observed, the application of focus group discussions has spread to several disciplines, including education.

The focus group discussions that included the families of children with CDB revealed, that parents showed greater display of emotions, for example, crying when talking about the difficult conditions they experience and the stigma they face. Although 'other' members of the group did not have such direct emotional experiences, they showed compassion in 
various ways with the parents, for example through moments of silence. After such moments the researcher could initiate another topic, providing these 'other' participants the opportunity to share their own experiences.

Conversely, in the focus groups that did not include the families of the children with CDB, participants felt freer to share their experiences and didn't feel the direct need to show compassion. In these discussions there was a more active flow with more turn-taking between the participants. In the DRC, for example, the researcher allowed the local traditional chief (Chef Coutumier) to lead the discussion for a certain amount of time. This change of role had a positive impact on the group dynamics, and participants expressed their pride that others were interested in hearing their social and traditional beliefs surrounding disability. This pride increased the chances of varied and more honest responses and suggestions from the participants (Nyumba et al, 2018).

\section{Study limitations}

The master study was limited and could cover only two countries (one each in Cetral and Eastern Africa). Additionally, there is relatively little relevant literature on the topic.

Furthermore, in the DCR there were no services at all for CBD. These general limitations posed challenges to this study.

Another limitation was the language and translation difficulties. Th available documents in the DRC were in French and translation to English sometimes failed to bring out the intended meaning.

Because of these general limitations the researcher had to develop a theoretical framework and study design from scratch, and succeeded in this. Methodological this study needs more replications, but the value of this study is very worthwhile.

Another limitation was the language and translation to English sometimes failed to bring out the intended meaning.

\section{Implications for further research}

This study is very original and innovative in the field of deafblindness (and even in the general field of special needs education). It delivers a good basis as exemplary case study for further studies (Markova, 2017).

During the data collection process, the focus groups that included the families of children with CBD from both countries observed greater displays of emotion form the parents, restricting other members of the group from expressing their honest and personal opinions about the topic at hand. These participants showed a feeling of hesitation in expressing their 
thoughts, especially when their thoughts opposed the views of the parents. It is important also for future research to taken this in account.

This study shown that, in Uganda and the DRC (and from the cant literature available about other countries in East Africa, such as Kenya, Tanzania and Zambia), no distinction is drawn between CBD and acquired deafblindness. It is possible that, due to cultural diversity, the education of CBD is perceived differently in each country.

Therefore, further research on a large scale is needed to analyse the social construction of CBD in central and eastern Africa. The outcome will allow international organizations and governments to understand different social realities and the real position of people with CBD.

The results may also be useful for policymakers in planning inclusive education.

\section{Implications for educational practice and policy}

The initial position taken in the research was that understanding different third voices, the underlying barriers, and tensions is a key element for a change of attitude to promote educational opportunities for people with CDB. In addition, awareness about CDB involving local, traditional, religious, and educational leaders is important. The study revealed that culture and religious beliefs have a significant influence on the education of people with CDB. To conclude, it is necessary for governments and NGOs working in the field of CDB to show initiative and responsibility in the education of people with CDB and work according a community-based approach.

Similarly, churches in Africa are key to initiate change. In countries such as the DRC, approximately $60 \%$ of schools are run by the church, with special education always handled by the church as an issue of charity (Ministry of Education-DRC, 2010). Special emphasis on awareness of disability in general and CDB in particular should be initiated by the church; the church can play an important role in changing the current situation. If the church understands the social realities surrounding people with $\mathrm{CDB}$, it can serve in the same way as international organizations described in the literature (United Nations, 1996) and use its authority to create positive attitudes and establish dynamic educational opportunities for people with CDB. Churches should also change their approach and not only focus on moral and spiritual support but also extend support to families with CDB. Thus, churches could identify educational needs and foster the educational development of people with CDB and establish parent-professional partnerships. 
These relationships can serve as a link and ensure that families with CDB and service providers such as international organizations and schools are connected and parents have support in gaining a full understanding of their children's strengths and needs.

\section{Acknowledgements}

The authors acknowledge the collaboration during data collection of Senses International Uganda and the Centre for Education and Community Based Rehabilitation (CERBC) DRC.

\section{Funding details}

This study is part of a Master's thesis of one year's Master program in Pedagogical Sciences on Communication and Congenital Deafblindness completed at the University of Groningen, thanks to the sponsorships from the Catholic Foundation for Blind and Partially Sighted People (KSBS) (Katholieke stichting voor blinden \& slechtzienden), the 'Stichting tot verbetering van het Lot der Blinden' the Netherlands, and the Dutch Ministry of Education, Culture and Science and Dutch Research Universities for the Holland Scholarship Award.

\section{Declaration of interest statement}

The authors declare no potential conflicts of interest with respect to the research.

\section{References}

Ary, D., Cheser, L. J., \& Sorensen, C. (2010). Introduction to research in education. $8^{\text {th }}$ Edition. Wadsworth Cengage Learning.

Bakhtin, M. (1970). La poétique de Dostoïevski. Paris. Points Seuil.

Baynton, D. (2006). "A silent exile on this Earth": The metaphorical construction of deafness in the nineteenth century. In Davis, J. L. (Ed.), The Disability Studies Reader (2nd ed., pp. 33-48). Library of Congress Cataloging-in-Publication Data

Berger, P. L., \& Luckman, T. (1966). The social construction of reality: A treatise in the sociology of knowledge. Penguin Books

Bunning, K., Gona, J. K., Newton, \& C. R., Hartley, S. (2017). The perception of disability by community groups: Stories of local understanding, beliefs and challenges in a rural $\begin{array}{lllll}\text { part of } & \text { Kenya. } & \text { ONES } & \text { 12(8): } & \text { 0182214. }\end{array}$ https://doi.org/10.1371/journal.pone.0182214

Burr, V. (2003). Social constructionism. Routledge.

Byaruhanga, I. K. (2018). Analysis of the social construction of congenital deafblindness in 
relation to education in East and Central Africa. Master thesis, Track Communication and Deafblindness. Groningen: University of Groningen.

Chandra, S. S. R., \& Sharma, R. K. (2004). Sociology of Education. Atlantic Publisher \& Distributors.

Charmaz, K. (2005). Constructing Grounded Theory. $2^{\text {nd }}$ ed. Sage Publications

Collins, M.T. (1993). Educational services: Presentation. Proceedings of the National Symposium on Children and Youth Who Are Deaf-Blind (pp. 165-178). Monmouth. OR: Teaching Resources Center, Western Oregon University.

Collins, M. T. (1995). History of deaf-blind education. Journal of Visual Impairment \& Blindness, 89(3), 210. doi.org/10.1177/0145482X9508900304

Crow, L. D., \& Crow, A. (1964). Educational psychology. Eurasia Publishing House Pvt, Ltd Czarniawska, B. (2004). Narratives in social science research. Introducing qualitative methods. Sage Publications. doi.org/10.4135/9781849209502

Dantona, R. M. (1971, August 22-27). Services for deaf-blind children. In serving deaf-blind children. Fourth international conference on deaf-blind children. Perkins School for the Blind Watertown, Massachusetts, USA.

Dewey, J. (1916). Democracy and education. An introduction to the philosophy of education. New York: MacMillan.

EDbN. (2014). Mapping opportunities for deafblind people across Europe. Government and voluntary sector responses to the growing issue of deafblindness in Europe. European Deafblind Network.

Eiesland, N. L. (1994). The disabled God: Toward a liberatory theology of disability. Abingdon Press.

European Agency for Special Needs and Inclusive Education (2013, Nov 8). Inclusive education in Europe: Putting theory into practice. https://www.europeanagency.org/sites/default/files/IC\%20Researchers\%20paper.pdf

Flores, J. G., \& Alonso, C. G. (1995). Using focus groups in educational research: Exploring teachers' perspectives on educational change Evaluation Review, 19(1), 84101. doi.org/10.1177/0193841X9501900104.

Gillespie, A., \& Cornish, F. (2009). Intersubjectivity: Towards a dialogical analysis. Journal for the Theory of Social Behaviour, 40(1), 19-46. ISBN-13: 9780132338776.

Hart, P. (2010). Moving beyond the common touch point discovering language with congenitally deafblind people. Doctoral dissertation. University of Dundee. https://discovery.dundee.ac.uk/ws/portalfiles/portal/1193330/Hart_phd 2010.pdf

Janssen M.J \& Rødbroe I. (2007). Communication and congenital deafblindness II: Contact and social interaction. VCDB/Viataal, Sint-Michielsgestel: Kentalis. 
Lane H., (2010). Construction of deafness. Disability \& Society. doi.org/10.1080/09687599550023633.

Larsen, F.A. \& Damen S. (2014). Definitions of Deafblindness and Congenital Deafblindness. Research in Developmental Disabilities, 35, (10). Doi: 10.1016/j.ridd.2014.05.029.

Linell, P. (1998). Approaching dialogue. Talk, interaction and contexts in dialogical perspectives. Amsterdam: John Benjamin Publishing Co. Handbook

Linell, P. (2009). Rethinking language, mind, and world dialogically. Interaction and contextual theories of human sense-making University of Linköping, Sweden https://www.infoagepub.com/products/Rethinking-Language-Mind-and-WorldDialogically

Marková, I., (2016). The dialogical mind: Common sense and ethics. Cambridge University Press.

Markova, I. (2017). Case studies and dialogicality. Journal of Deafblind Studies on Communication, 3, (1), 28-45.

MacDonald, A. S. (2012). Cultural beliefs about disability in practice: Experiences at a special school in Tanzania. International Journal of Disability, Development and Education. 59(4). doi.org/10.1080/1034912X.2012.723947

McInnes, J. M. (1999). Deafblindness: A unique disability. A Guide to planning and support for individuals who are deafblind (pp. 3-32). University of Toronto Press.

McLetchie, B. A. B. (1993). Staff preparation: presentation. Proceedings of the national symposium on children and youth who are deaf-blind. Teaching Resources Center, Western Oregon University. 180-196.

Michalko, R. (2002). The difference that disability makes. Temple University Press.

Mji, G., Kalenga, R., Ned, L., Alperstein, M. \& Banda, D. (2017). Indigenous knowledge, exclusion in education systems of Africans: Impact of beingness and becoming an African. Handbook of research on social, culture and educational considerations of indigenous knowledge in developing countries. British Cataloguing in Publication Data. pp. 37-47.

Ministry of Education-DRC. (2010). Stratégie de développement de l'enseignement primaire, secondaire et professionnel (2010/11 - 2015/16). Pp15. https://planipolis.iiep.unesco.org/sites/default/files/ressources/congodrstrategie20 102016.pdf

Nafstad, A. \& Rødbroe, I. (2015). Kommunikative Beziehungen. Interventionen zur Gestaltung von Kommunikation mit Menschen mit angeborener. Taubblindheit. Edition Bentheim. Würzburg, pp. 3-231.

Nyumba, T. O., Wilson, K., Derrick, C. J., \& Nibedita Mukherjee, N. (2018). The use of 
focus group discussion methodology: Insights from two decades of application in conservation. Methods in Ecology and Evolution, 9(1), 20-32.doi.org/10.1111/2041210X.12860

Obioha, E. E. \& T'soeunyane, P. G. (2012). The roles of the elderly in Sotho family system and society of Lesotho, Southern Africa. Kamla-Raj Anthropology, 14(3), 251-260. doi: 10.1080/09720073.2012.11891246

Omugur, J. P. \& Bunyasi, A. B. (2016). Teachers' use of communication techniques for achievement of daily living activities by learners with deafblindness in primary schools, Uganda. International Journal of Education and Research.4(9).175-184. ISSN: 2411-5681. https://www.ijern.com/journal/2016/September-2016/16.pdf

Orodho, A. J. (2012). Techniques of writing research proposals \& reports in education and social sciences. Kanezja Publishers. IBN 9966-7350-0-3.

Peek, P. M. (2011). Twins in African and diaspora cultures. Indiana University Press.

Peters, R. S. (1975). The philosophy of education. London: Oxford University Press.

Riddell, S., \& Watson, N. (2014). Disability, culture and identity. Pearson Education Limited.

Rødbroe I. \& Janssen, M. (2006). Communication and Congenital Deafblindness. Congenital deafblindness and the core principals of intervention. VCDB/Viataal. SintMichielsgestel: Kentalis.

Shakespeare, T. (2014). Disability rights and wrongs revisited. $1^{\text {st }}$ ed. London: Routledge.

Signo Foundation. (2014). Baseline survey on the living conditions for deafblind persons in the southern part of Malawi. Chisombezi deafblind centre Malawi.

Souriau, J. (2000). Introduction : surdi-cécité et développement de la communication. Enfance, $n^{\circ} 1 . \quad$ pp. 3-18. https://www.persee.fr/issue/enfan_00137545_2000_num_53_1?sectionId=enfan_0013-7545_2000_num_53_1_3165

Souriau, J. (2002). Sensation, perception and formation of meaning - What does it mean when people are congenitally deafblind?. Communication Network Update Service (CNUS), no. 3. Dronninglund, Dänemark: Nordic Staff Training Centre for Deafblind Services. http://www.nordicwelfare.org/filearchive/8/87909/CNUS03.pdf

Souriau, J. (2007). La surdicécité : les voix de la nuit et du silence. Colloque SHADOC 5 - 6 Décembre.

Spradley, J. P. (1980). Participant observation. Library of Congress Cataloging in 67 Publication Data. p. 183

UNICEF-Uganda. (2014). Situational analysis on the rights of children with disabilities in Uganda.p. 83

United Nations. (1966). The International Convention on Economic, Social and Cultural. ICESCR, Article 13.1 
United Nations. (2006). Convention on the rights of persons with disabilities. New York: United Nations

van Dijk, J. (1997). History and change in the education of children who are deaf-blind since the Rubella epidemic of the 1960s: Influence of methods developed in the Netherlands. DeafBlind Perspectives. Volume 5 Issue.

World Health Organisation. (2011). World report on disability. Geneva: World Health Organization.

Ismael K. Byaruhanga, Audiologist and Executive Director of the Centre for Education and Communitybased Rehabilitation in the Northern Democratic Republic of the Congo; MSc Communication and Deafblindness, University of Groningen (The Netherlands); PhD candidate at the University of Cologne in Germany;

email: <Byaruhangakus. ismael@yahoo. com>

Anne V. Nafstad, Psychologist, Department of Deafblindness and Combined Visual and Hearing Impairment STATPED Southeast, Oslo, Norway, Former Lecturer, Department of Inclusive and Special Needs Education, University of Groningen, Netherlands

Jacques Souriau, Psychologist, Former Lecturer, Department of Inclusive and Special Needs Education, University of Groningen, Netherlands 